\title{
Interpersonal Effects of Strategic and Spontaneous Guilt Communication in Trust Games
}

\author{
Danielle M Shore and Brian Parkinson \\ Department of Experimental Psychology \\ University of Oxford \\ Tinbergen Building \\ 9 South Parks Road \\ Oxford, OX1 3UD \\ +44 (0) 1865271335
}

danielle.shore@psy.ox.ac.uk, brian.parkinson@psy.ox.ac.uk

Corresponding author: Danielle M Shore, ORCiD 0000-0001-7290-3696

Word Count: 4000

Figures: 2

References: 15

Abstract: 92

Disclosure of interest: The authors report no conflicts of interest.

Running Head: GUILT AND STRATEGIC REGULATION IN TRUST

This research was supported financially by the Economic and Social Research Council grant ES/L016486/1 awarded to Brian Parkinson. 


\begin{abstract}
A social partner's emotions communicate important information about their motives and intentions. However, people may discount emotional information that they believe their partner has regulated with the strategic intention of exerting social influence. Across two studies, we investigated interpersonal effects of communicated guilt and perceived strategic regulation in trust games. Results showed that communicated guilt (but not interest) mitigated negative effects of trust violations on interpersonal judgements and behaviour. Further, perceived strategic regulation reduced guilt's positive effects. These findings suggest that people take emotionregulation motives into account when responding to emotion communication.
\end{abstract}

Keywords: Trust, emotion, guilt, regulation, decision-making, interpersonal appraisal 


\section{Interpersonal Effects of Strategic and Spontaneous}

\section{Guilt Communication in Trust Games}

At one time or another, everyone falls short of a social partner's expectations, undermining interpersonal trust. The emotions communicated after such transgressions significantly impact subsequent interactions. For example, guilt can help repair relationship damage and facilitate trust (Baumeister, Stillwell, \& Heatherton, 1994). Indeed, people may up-regulate guilt expression with the strategic intention of achieving these interpersonal effects (e.g. Barry, 1999). Correspondingly, interaction partners may factor in possible regulation when appraising communicated guilt. They may wonder whether their partner is genuinely sorry or simply trying to solicit forgiveness. Under these circumstances, perceiving communicated guilt as regulated may undermine its ability to repair trust, making future cooperation less likely.

\section{Trust and Emotion}

Interpersonal trust is elemental for everyday interactions, even in one-off, short-term exchanges. Although observed behaviour provides the firmest basis for trust (King-Casas et al., 2005), emotion communication also plays a significant role (e.g. de Melo, Carnevale, Read, \& Gratch, 2014). By conveying information about motives, expressed emotions can affect interpersonal appraisals and decision-making processes (Manstead \& Fischer, 2001).

Previous research shows that expressions communicating cooperative intentions (e.g. regret after transgression) lead to greater trust and cooperation (de Melo et al., 2014). The present studies investigated interpersonal effects of communicated guilt in relation to trust decisions. Expressed guilt is important for repairing trust because it communicates that the transgressor feels sorry and has 
positive intentions (Baumeister et al., 1994). Consequently, people communicating guilt are appraised more favourably (Van Kleef, De Dreu \& Manstead, 2006) and as more likely to be trustworthy in future. Accordingly, guilt expressions increase other players’ generosity in economic games (de Melo, Carnevale, \& Gratch, 2012).

\section{Emotion Regulation}

In economic games, players may regulate their emotion communication in order to influence the other player’s behaviour (Barry, 1999). Correspondingly, the other player may discount emotional information that they believe has been strategically regulated. Previous research provides initial evidence that regulated emotion communication diminishes interpersonal trust (e.g., Caza, Zhang, Wang, \& Bai, 2015; Kim, Mislin, Tuncel, Fehr, Cheshin, \& van Kleef, 2017) and moderates emotion’s impact on decision-making. For example, authentic anger increases concessions in negotiations, whereas inauthentic anger reduces concessions (Côté, Hideg, \& Van Kleef, 2013). Correspondingly, perceivers’ beliefs that guilt communication is strategically regulated may undermine its usual relational repair effects. Our research tests this prediction.

\section{The Present Research}

We modeled trust between strangers using trust games (Berg, Dickhaut, \& McCabe, 1995), in which an investor decides how much of a resource to send to a trustee. The invested amount immediately matures (e.g. is multiplied by 3), and the trustee decides how much of the matured investment to send back. The amount invested depends on the investor's perception of the trustee's trustworthiness, whereas the amount returned depends on the trustee’s actual trustworthiness.

The present studies assessed effects of trustees' communicated emotion and perceived strategic regulation on investors' subsequent resource allocations. The 
trustee's initial trust violation should reduce the investor's willingness to trust them again, as indexed by the level of subsequent investment (King-Casas et al., 2005). We hypothesised that communicated guilt would facilitate interpersonal trust after a transgression (Baumeister, et al., 1994), even under these restrictive conditions. Our specific prediction was that trustees reporting guilt following unfair behaviour would subsequently receive higher investments than trustees reporting interest. Interest was selected as comparison emotion because it communicates appraisal of the preceding event as positively relevant (Clement \& Dukes, 2013).

We also assessed whether perceiving communicated guilt as strategically regulated would reduce its trust-repairing effects. In both studies, we informed participants that trustees were either aware (strategic condition), or unaware (spontaneous condition) that their emotions would be communicated. In the former case, we expected participants to infer that any communicated emotion was potentially regulated. Therefore, we predicted that trustees reporting guilt in the spontaneous condition would receive higher investments and be seen as more trustworthy than trustees reporting guilt in the strategic condition.

\section{Experiment 1}

\section{Method}

\section{Participants}

We recruited 302 participants (130 female, $\left.M_{\text {age }}=35.12, S D=10.52\right)$ through Amazon Mechanical Turk. Each was paid \$3 and given the opportunity to win money in a lottery.

\section{Design}

Experiment 1 utilized a 2 (trustee emotion: guilt vs. interest) $\times 2$ (perceived regulation: strategic vs. spontaneous) between-participants design, with random 
assignment to conditions. The main dependent measures were investments in rounds 1 and 2 and ratings of the trustee.

\section{Procedure}

Using an ostensibly random procedure, participants were assigned the role of investor in an online trust game. The Qualtrics (Provo, UT) program collected demographic information before indicating that another participant was online to take the role of trustee in a two-round trust game. In fact, this other participant's responses were preprogrammed. In the strategic condition, we informed players that the investor would see the trustee's highest rated emotion after round 1, and that the trustee was aware of this communication. ${ }^{1}$ By contrast, instructions in the spontaneous condition stated that the trustee was unaware that emotion information would be communicated.

Participants received 100 lottery tickets before each round and selected how many to transfer to the trustee. The computer then displayed the matured investment (initial investment X 3) and instructed participants to wait to see how many tickets were returned by the trustee, which appeared after a brief delay. In round 1, this number was less than the original investment (30\% of the matured investment). The participant was then shown the trustee’s highest-rated emotion. Depending on emotion condition, this rating indicated either moderate guilt or interest (see Figure 1).

Next, participants completed a short questionnaire about the trustee's behaviour and personality. They were informed that no emotion information would be

\footnotetext{
1 Pilot work suggested that participants did not always consider the possibility that communicated emotion ratings might misrepresent actual feelings. Therefore, to make this possibility more salient and increase the likelihood that participants would consider strategic regulation motives, all participants completed a short emotional honesty questionnaire alongside the demographic questions (8 items, e.g. "People always express what they truly feel" and "Most people are strategic in how they express their emotions").
} 
communicated in round 2, in which all returns were fair ( $50 \%$ of the matured investment). $^{2}$

To enhance involvement, we told participants that lottery tickets increased their chances of winning a prize of up to $£ 100$. Because participants actually had no control over returns, we entered all participants in the lottery once, and randomly selected 6 as winners.

\section{Measures}

Participants rated how good and how sorry the trustee felt, how trustworthy, socially oriented (friendly, outgoing, kind) they were and how authentic their communication of emotion had been, immediately after the post-round-1 emotion communication. All ratings used 5-point Likert scales from 1 (Not at all) to 5 (Extremely). The three social orientation items (friendly, outgoing, kind, $\alpha=.86$ ) and the six emotional authenticity items ("the trustee genuinely expressed their feelings", "the trustee was faking how they felt” (reverse scored; R), “the trustee was pretending to feel something that they didn't” (R), "the trustee was sincere”, "the feeling the trustee reported was not real” (R), and "the trustee reported feelings they did not really feel inside” (R), adapted from Côté, et al., 2013, $\alpha=.92$ ) were combined into separate scales. $^{3}$

\footnotetext{
${ }^{2}$ At the end of the procedure, we also checked for suspicion by asking participants to what extent they doubted that the other player's behaviour was real. Adding this as a continuous independent variable to the ANOVA of investment behaviour revealed that it had no significant interactions with the manipulated independent variables in either experiment, suggesting that it did not moderate the reported effects.

${ }^{3}$ We also asked these questions after the second round, but we do not report these data because they reflect responses to the fair outcome administered by the trustee, and do not correspond to the time-point of participants' investment at T2. In addition, participants completed the Positive and Negative Affect Schedule (Watson et al., 1988), and a series of questions assessing fairness, expectations, and how much they liked the other player after each round. These measures were completed by participants in both experiments, but are not directly relevant to the main focus of this article.
} 


\section{Results}

All ANOVAs employed a 2×2 between-participants design with emotion (guilt or interest) and perceived regulation (strategic or spontaneous) as factors.

\section{Manipulation Checks}

As intended, the emotion manipulation had a significant effect on ratings of how good trustees felt after round 1 , with trustees rated as feeling worse in the guilt condition $(M=2.89, S D=1.03)$ than in the interest condition $(M=3.88, S D=0.92)$, $F(1,298)=79.76, p<.001, \eta_{p}^{2}=.21$. Trustees were also rated as feeling worse in the spontaneous condition $(M=3.31, S D=1.12)$ than in the strategic condition $(M=$ 3.52, $S D=1.06, F(1,298)=3.68, p=.050, \eta_{p}^{2}=.01$.

The emotion manipulation also had the intended significant main effect on ratings of how sorry the trustee felt, $F(1,298)=105.74, p<.001, \eta_{p}^{2}=.26$, with guilty trustees rated as sorrier $(M=3.15, S D=0.95)$ than interested trustees $(M=$ 2.08, $S D=0.90)$. Further, there was a significant interaction between emotion and perceived regulation, $F(1,298)=4.87, p=.017, \eta_{p}{ }^{2}=.02$. Participants rated guilty trustees as sorrier in the spontaneous $(M=3.31 S D=0.90)$ than in the strategic condition $(M=3.01, S D=0.97, p=.059)$, but ratings of interested trustees did not differ across perceived regulation conditions (spontaneous $M=1.96, S D=0.90$; strategic $M=2.17, S D=0.88, p=.135)$. Thus, our regulation manipulation successfully moderated emotion's effects on perceived sorrow.

Finally, participants rated trustees’ emotion reports as significantly less authentic in the guilt condition $(M=3.48, S D=1.08)$ than in the interest condition $(M$ $=3.81, S D=0.89), F(1,298)=6.75, p=.010, \eta_{p}{ }^{2}=.02$. This effect was qualified by a significant emotion by perceived regulation interaction, $F(1,298)=4.45, p=.036$, $\eta_{p}{ }^{2}=.02$. In the guilty condition, participants rated the emotion reports of strategic 
trustees as significantly less authentic $(M=3.33, S D=1.13)$ than those of spontaneous trustees $(M=3.68, S D=0.99, p=.038)$. However, in the interest condition, authenticity ratings did not differ across perceived regulation conditions (spontaneous $M=3.86, S D=0.90$; strategic $M=3.73, S D=0.88 ; p=.397$ ). Thus, the perceived regulation manipulation had its intended effect in the guilt condition.

\section{Interpersonal Judgements}

Perceived regulation also had a significant main effect on trustworthiness ratings, $F(1,298)=4.09, p=.044, \eta_{p}^{2}=.01$, showing that trustees were perceived as more trustworthy in the spontaneous condition $(M=2.49, S D=1.07)$ than in the strategic condition $(M=2.24, S D=1.05)$. Similarly, trustees were rated as significantly more socially oriented in the spontaneous condition $(M=2.77, S D=$ $0.86)$ than in the strategic condition $(M=2.48, S D=0.84), F(1,298)=8.16, p=.005$, $\eta_{p}{ }^{2}=.03$. However, emotion was involved in no significant effects on either measure.

\section{Investment Behaviour}

Investments were analysed using a mixed ANOVA, with round (1 vs. 2) as an additional within-participants factor. Investments were significantly higher in round 1 $(M=64.57, S D=29.98)$ than $2(M=45.61, S D=35.84), F(1,298)=61.68, p<.001$,

$\eta_{p}{ }^{2}=.17$. The interaction between round and emotion was also significant, showing that round-2 investments decreased less for guilty than for interested trustees, $F(1$, 298) $=4.83, p=.029, \eta_{p}^{2}=.02($ see Figure $2 \mathrm{a})$.

The predicted three-way interaction was marginally significant, $F(1,298)=$ 3.41, $p=.066, \eta_{p}{ }^{2}=.01$. To decompose this interaction, we ran separate $2 \mathrm{x} 2$ ANOVAs for both emotion conditions. The round-by-perceived-regulation interaction was significant in the guilt condition, $F(1,135)=5.54, p=.020, \eta_{p}{ }^{2}=.04$, but not in the interest condition. $F(1,135)=0.04, p=.841, \eta_{p}{ }^{2}=.00$. 
Planned simple effects analysis further clarified the interaction. Investments decreased significantly from round 1 to 2 in both interest conditions (spontaneous $F(1,298)=24.72, p<.001, \eta_{p}{ }^{2}=.08$, strategic $F(1,298)=31.73, p<.001, \eta_{p}{ }^{2}$ $=.10)$, and in the strategic guilt condition $\left(F(1,298)=18.80, p<.001, \eta_{p}{ }^{2}=.06\right)$, but not in the spontaneous guilt condition, $F(1,298)=1.57, p=.211, \eta_{p}{ }^{2}=.01$.

\section{Discussion}

Following a trust violation, the trustee's communicated emotion significantly affected the investor's behaviour, with guilt communication increasing subsequent investment as predicted. This supports the idea that guilt serves an appeasement function and thereby mitigates the impact of negative behaviour (Baumeister et al., 1994). Participants also rated guilty trustees as feeling sorrier about their behaviour, which may have increased expectations of future returns.

Interested trustees’ emotion reports were also rated as more authentic than those of guilty trustees, possibly because guilt is a more normative reaction to behaving unfairly. Interest implies that the trustee is not simply adjusting to normative demands, making their emotion communication seem more authentic. Despite this, guilty trustees still received higher investments than interested trustees.

Perceived regulation had less consistent effects than emotion. As intended, participants in the strategic guilt condition rated trustees as less sorry and their emotion reports as less authentic than participants in the spontaneous guilt condition. Perceived regulation also had significant effects on trustworthiness and social orientation scores, and on ratings of how bad the trustee felt after the trust violation. Across emotion conditions, spontaneous trustees were rated as more trustworthy and socially oriented than strategic trustees. These findings support our predictions for the guilt condition, but the interest condition effect was unexpected. The most likely 
explanation is that the trust violator's apparent willingness to communicate interest rather than remorse implies little regard for the participant's feelings. This might also explain why ratings of how bad the trustee felt were also significantly lower in this condition.

The predicted three-way interaction effect on investments was only marginally significant. However, perceived regulation significantly moderated the effect of round in the guilt condition but not in the interest condition. Further, the only condition where investments did not decrease significantly across rounds was the spontaneous guilt condition. These findings are generally consistent with our proposal that perceiving guilt communication as regulated reduces its reparatory effects. Further, the overall pattern of results across dependent measures clearly shows that participants take the possibility of strategic emotion communication into account when making judgements and deciding whether to trust other players.

\section{Experiment 2}

Experiment 1 showed that communicated emotions significantly affect interpersonal judgements and behaviour, but the lack of a control condition made it unclear whether effects reflected guilt's positive influence, interest's negative influence, or both. Experiment 2 therefore included a neutral condition.

\section{Method}

\section{Participants}

We recruited 293 participants (131 female, $\left.M_{\text {age }}=34.23, S D=10.78\right)$ through Amazon Mechanical Turk, using identical incentives to experiment 1.

\section{Procedure}

The only procedural change was that experiment 2's emotion manipulation had 3 levels following the addition of a neutral condition, in which trustees' highest 
rated emotion was "neutral."

\section{Measures}

Measures were identical to experiment 1 . Social orientation $(\alpha=.87)$ and authenticity scales $(\alpha=.90)$ again showed good reliability.

\section{Results}

All ANOVAs employed a 3×2 between-participants design with emotion (guilt, interest or neutral) and perceived regulation (strategic or spontaneous) as factors.

\section{Manipulation Checks}

A significant main effect of the emotion manipulation confirmed that participants rated guilty trustees as feeling worse $(M=2.50, S D=0.80)$ than either neutral $(M=3.47, S D=0.85, p<.001)$ or interested $(M=3.92, S D=0.89, p<.001)$ trustees, $F(2,284)=72.05, p<.001, \eta_{p}^{2}=.34$. Similarly, guilty trustees were rated as sorrier $(M=3.55, S D=0.81)$ than either interested $(M=2.28, S D=0.92)$ or neutral trustees $(M=2.45, S D=0.74), F(1,284)=67.00, p<.001, \eta_{p}{ }^{2}=.32$. No other main or interaction effects were significant in either analysis.

Confirming the success of the perceived regulation manipulation, spontaneous trustees' emotion reports $(M=3.92, S D=0.85)$ were rated as significantly more authentic than those of strategic trustees $(M=3.61, S D=0.97), F(1,284)=9.70, p$ $=.002, \eta_{p}{ }^{2}=.03$, but the interaction between emotion and perceived regulation was non-significant. Guilty trustees’ emotion reports were also rated as significantly less authentic $(M=3.48, S D=1.02)$ than those of either neutral $(M=3.84, S D=0.91, p$ $=.004)$ or interested trustees $(M=3.97, S D=0.77, p<.001)$, but authenticity ratings for interested and neutral trustees did not differ $(p=.310), F(2,284)=8.63, p<.001$, $\eta_{p}^{2}=.06$ 


\section{Interpersonal Judgements}

Perceived regulation again had significant main effects on both trustworthiness and social orientation judgements, with spontaneous trustees rated higher on both variables (trustworthiness $M=2.43$, $S D=1.09$; social orientation $M=$ $2.61, S D=0.96$ ) than strategic trustees (trustworthiness $M=2.17, S D=1.08$; social orientation $M=2.38, S D=0.93), F(1,284)=4.10, p=.044, \eta_{p}^{2}=.01$ and $F(1,284)=$ 4.23, $p=.041, \eta_{p}^{2}=.02$, respectively. No other main effects or interactions were significant.

\section{Investment Behaviour}

A $3 \times 2 \times 2$ mixed ANOVA showed that investments were significantly lower in round 2 than $1, F(1,284)=53.22, p<.001, \eta_{p}{ }^{2}=.16$. A round by emotion interaction indicated that round-2 investments were higher to guilty trustees than to interested or neutral trustees, $F(1,284)=3.53, p=.031, \eta_{p}{ }^{2}=.02$, see figure $2 b$. This again supports our prediction that guilt communication moderates the negative impact of unfair behaviour.

The predicted three-way interaction was not significant, $F(1,284)=1.92, p$ $=.149, \eta_{p}{ }^{2}=.01$. However, we again used planned simple effects of round to assess further whether spontaneous guilt mitigated effects of unfair behaviour. Again, investments decreased significantly (or near-significantly) in all conditions (spontaneous interest $F(1,284)=6.14, p=.014, \eta_{p}{ }^{2}=.02$; strategic interest $F(1,284)$ $=25.11, p<.001, \eta_{p}^{2}=.08$; spontaneous neutral $F(1,284)=19.83, p<.001, \eta_{p}^{2}$ $=.07$; strategic neutral $F(1,284)=9.09, p=.003, \eta_{p}{ }^{2}=.03$; strategic guilt $F(1,284)$ $\left.=3.56, p=.060, \eta_{p}{ }^{2}=.01\right)$ apart from the spontaneous guilt condition, $F(1,284)=$ $1.01, p=.315, \eta_{p}^{2}=.004$. 


\section{Discussion}

Experiment 2 again showed that guilt diminished the negative effect of a transgression on investments, and that this effect was strongest in the spontaneous guilt condition. Further, neutral and interest conditions were not significantly different, suggesting that our effects depend on guilt's positive interpersonal impact rather than interest’s negative interpersonal impact.

Our regulation manipulation again had significant effects on the trustee’s perceived emotional authenticity, trustworthiness, and social orientation across emotion conditions. As before, regulated guilt communication probably undermined the emotion's trust-repairing effects because it was perceived as a strategic influence attempt. By contrast, knowingly communicating interest or neutrality following trust violation probably increased perceptions of social insensitivity.

\section{General Discussion}

These studies show that guilt repairs trust after transgressions, and increases trust-related behaviour even in games played with strangers, where interpersonal expectations are typically low. Our results also suggest that perceiving communicated guilt as regulated may undermine its trust-repairing effect. Thus, people may discount the implications of a communicated emotion if they believe that communication was strategically regulated and therefore inauthentic.

Following previous research (e.g., Kugler, Bornstein, Kocher, \& Sutter, 2007), these experiments used trust-game investments as indications of interpersonal trust. Although other factors, such as participants’ fairness beliefs, may also have influenced investment, most of these effects are likely to stay consistent across rounds and not affect change in investment. To supplement the behavioural measure, we also 
measured ratings of trustworthiness, which confirmed that regulated emotions generally reduced trust.

It is important to acknowledge that the interaction between perceived regulation, emotion, and round showed at best a marginally significant effect on investments. However, planned contrast analyses demonstrated that investments decreased significantly from round 1 to 2 in all conditions apart from the spontaneous guilt condition across studies. This suggests that guilt communication has stronger interpersonal effects when it is perceived as unregulated. However, this conclusion awaits further evidence, especially given that the effect sizes were generally small. Despite this, these experiments add to a growing body of literature that suggests the perception of emotions as strategically regulated has important implications for interpersonal trust and decision-making (e.g., Caza et al., 2015; Kim et al., 2017).

In experiment 1 , it is also possible that pre-manipulation differences in round 1 investments across conditions contributed to the reported interactions, despite the fact that they were non-significant (see Figure 2). However, this was clearly not the case in experiment 2, where any round 1 differences worked against our reported effects, perhaps helping to explain why the predicted three-way interaction was nonsignificant.

Another reason why regulation's effects were less consistent than those of emotion may be that some participants may have perceived trustee's regulated guilt communication as an acknowledgement that they should feel bad about violating trust. This raises the interesting question of whether motives for emotion regulation (Tamir, 2016) moderate its interpersonal effects. For example, other people may react more favourably to emotion regulation motivated by prosocial rather than egoistic 
concerns (see Niven, 2016). Future research should independently assess perceived regulation and perceived motives to address this issue.

Even with these caveats, our findings across dependent variables and studies suggest that both communicated emotion and beliefs about motives for

communication influence trust. Further, the effects on trustees’ perceived sorrow and authenticity suggest that people are aware that emotion communication may be manipulated, and factor this into their appraisals. Future studies should use dynamic guilt expressions to provide stronger cues of potential regulation.

\section{Limitations}

One limitation of these studies is that participants played games online with no possibility of meeting the other player, minimizing any risk of negative social consequences. Further, participants knew that the second round was the last, reducing any incentive to reciprocate trust in anticipation of future benefits. Investors may therefore have limited investments because they expected trustees to behave selfishly (Cochard, Van, \& Willinger, 2004), working against our predicted effects. Future experiments should assess effects of regulated and unregulated guilt communication over multi-round games.

The trust violation used in these studies carried no serious consequences. Previous research suggests that effectiveness of repair tactics depend on transgression severity (Bennett \& Earwaker, 1994). Thus, future research should also manipulate this factor to assess whether guilt has weaker effects following more consequential violations.

Because guilt was the only negative emotion manipulated here, some effects may have depended on valence rather than specific emotional quality. However, previous research shows that distinct same-valence emotions differentially affect 
decisions (e.g. Lerner \& Keltner, 2000), and that guilt produces the particular form of relational repair we observed (Baumeister et al., 1994). In our view, guilt's reparative power specifically depends on it communicating self-blame following transgressions.

\section{Conclusions}

Two studies assessed whether expressed emotions and perceived regulation influence interpersonal trust. Results showed that guilt communication serves an appeasement function, mitigating a transgression's impact and leading to greater interpersonal trust than comparison conditions. However, guilt's positive effects are potentially diminished by perceptions that its communication is strategically regulated. In this case, individuals may factor possible motives into their appraisal affecting subsequent behavioural response. This has important implications for understanding how trust operates in more realistic economic contexts. 


\section{Acknowledgements}

The authors would like to thank Magdalena Rychlowska for her helpful comments on an earlier version of this article. 


\section{References}

Baumeister, R.F., Stillwell, A.M., \& Heatherton, T.F. (1994). Guilt: an interpersonal approach. Psychological Bulletin, 115(2), 243-267. doi:10.1037/00332909.115.2.243

Barry, B. (1999). The tactical use of emotion in negotiation. In R. J. Bies \& R. J. Lewicki (Eds.), Research in negotiation in organizations (Vol. 7, pp. 93121). Stamford, CT: JAI Press.

Berg, J., Dickhaut, J., \& McCabe, K. (1995). Trust, reciprocity, and social history. Games and Economic Behaviour, 10(1), 122-142. doi:10.1006/game.1995.1027

Bennett, M., \& Earwaker, D. (1994). Victims' responses to apologies: The effects of offender responsibility and offense severity. The Journal of Social Psychology, 134(4), 457-464. doi:10.1080/00224545.1994.9712196

Caza, A., Zhang, G., Wang, L., \& Bai, Y. (2015). How do you really feel? Effect of leaders' perceived emotional sincerity on followers' trust. The Leadership Quarterly, 26(4), 518-531. doi:10.1016/j.leaqua.2015.05.008

Clément, F., \& Dukes, D. (2013). The role of interest in the transmission of social values. Frontiers in Psychology, 4. 349. doi:10.3389/fpsyg.2013.00349

Cochard, F., Van, P.N., \& Willinger, M. (2004). Trusting behaviour in a repeated investment game. Journal of Economic Behaviour \& Organization, 55(1), 31-44. doi:10.1016/j.jebo.2003.07.004

Côté, S., Hideg, I., \& van Kleef, G.A. (2013). The consequences of faking anger in negotiations. Journal of Experimental Social Psychology, 49(3), 453-463. doi:10.1016/j.jesp.2012.12.015 
de Melo, C., Carnevale, P., Read, S., \& Gratch, J. (2012). Reverse appraisal: The importance of appraisals for the effect of emotion displays on people's decision-making in a social dilemma. In Proceedings of 34th Annual Meeting of the Cognitive Science Society.

de Melo, C.M., Carnevale, P.J., Read, S.J., \& Gratch, J. (2014). Reading people’s minds from emotion expressions in interdependent decision making. Journal of Personality and Social Psychology, 106, 73-88. doi:10.1037/a0034251

Kim, P.H., Mislin, A., Tuncel, E., Fehr, R., Cheshin, A., \& van Kleef, G.A. (2017). Power as an emotional liability: Implications for perceived authenticity and trust after a transgression. Journal of Experimental Psychology: General, 146(10), 1379-1401.

King-Casas, K., Tomlin, D., Anen, C., Camerer, C.F., Quartz, S.R., Montague, P.R. (2005). Getting to know you: Reputation and trust in a two-person economic exchange. Science, 208, 78-83. doi:10.1126/science.1108062

Kugler, T., Bornstein, G., Kocher, M.G., \& Sutter, M. (2007). Trust between individuals and groups: Groups are less trusting than individuals but just as trustworthy. Journal of Economic Psychology, 28(6), 646-657. doi:10.1016/j.joep.2006.12.003

Lerner, J.S., \& Keltner, D. (2000). Beyond valence: Toward a model of emotionspecific influences on judgement and choice. Cognition \& Emotion,14(4), 473-493. doi:10.1080/026999300402763

Manstead, A.S.R., \& Fischer, A.H. (2001). Social appraisal: The social world as object of and influence on appraisal processes. Appraisal processes in emotion: Theory, methods, research (pp. 221-232). New York and Oxford: Oxford University Press. 
Niven, K. (2016). Why do people engage in interpersonal emotion regulation at work? Organizational Psychology Review, 6(4), 305-323.

Tamir, M. (2016). Why do people regulate their emotions? A taxonomy of motives in emotion regulation. Personality and Social Psychology Review, 20(3), 199-222.

Van Kleef, G.A., De Dreu, C.K., \& Manstead, A.S.R. (2006). Supplication and appeasement in conflict and negotiation: The interpersonal effects of disappointment, worry, guilt, and regret. Journal of Personality and Social Psychology, 91(1), 124-142. doi:10.1037/0022-3514.91.1.124 


\section{Figure Captions}

Figure 1. Round 1 timeline. Feedback is from the spontaneous guilt condition.

Figure 2. Mean investment in round 1 and round 2 of the trust game, according to the emotion displayed and perceived trustee regulation in (A) Experiment 1 and (B) Experiment 2. Error bars indicate 95\% CI. 
Figure 1

Round 1 Timeline

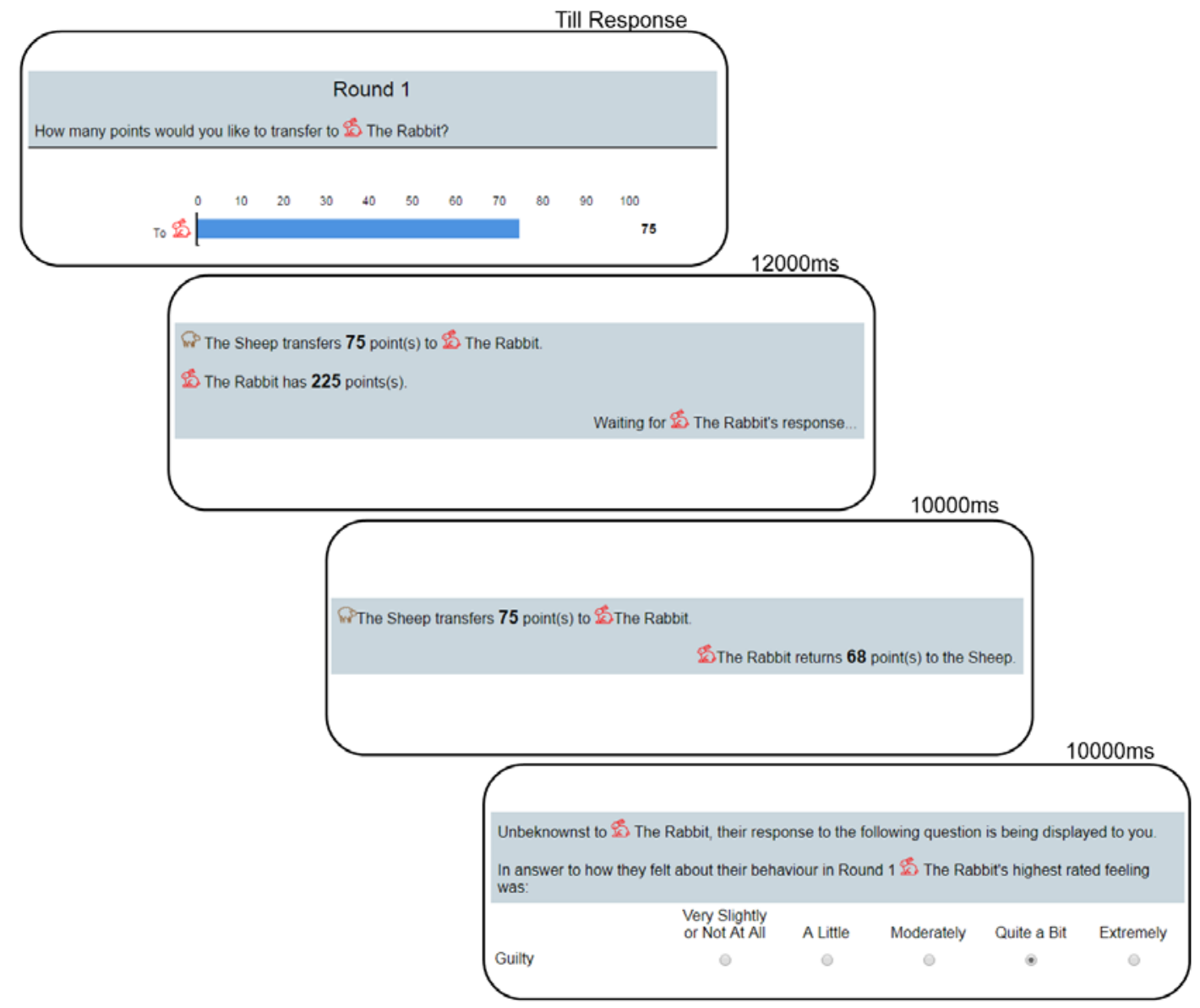


Figure 2

A

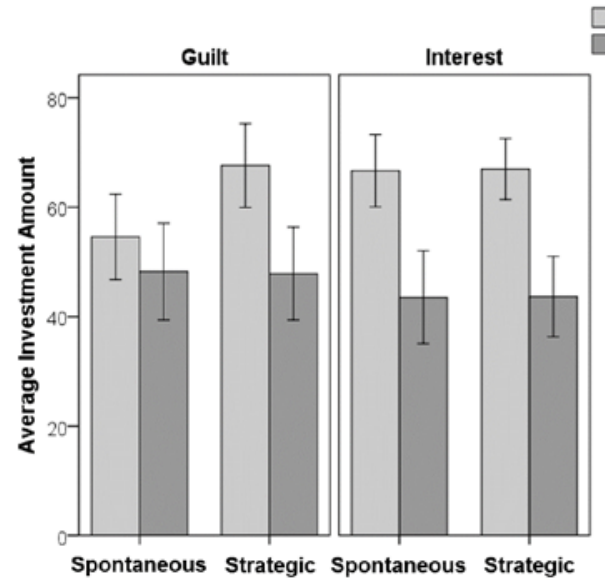

B

$\square$ Round 1 Round 2

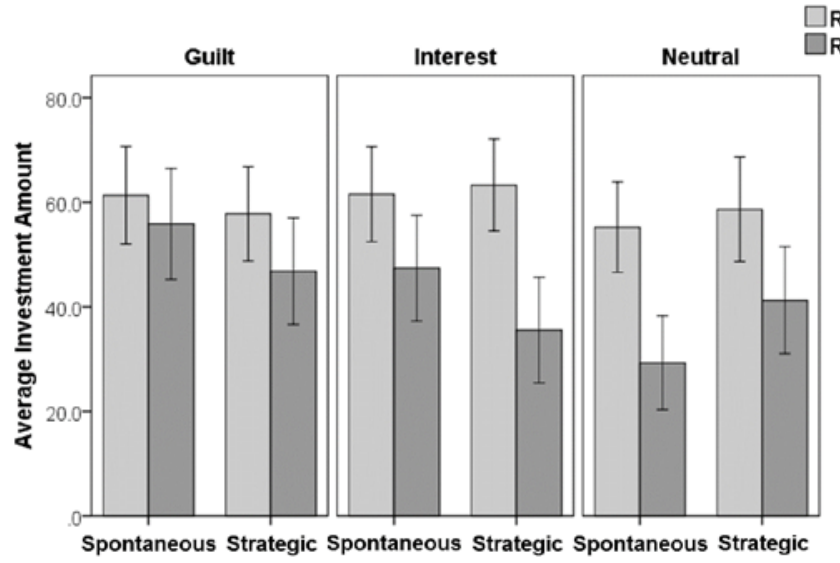

